\title{
Aesthetic Education for Young Children in Taiwan: Importance and Purpose
}

\author{
Yi-Huang Shih ${ }^{1}$ \\ ${ }^{1}$ Department of Early Childhood Educare, Ching Kuo Institute of Management and Health, Keelung, Taiwan \\ Correspondence: Yi-Huang Shih, Department of Early Childhood Educare, Ching Kuo Institute of Management \\ and Health, Keelung, Taiwan. Tel: 886-2-2437-2093. E-mail: shih262@gmail.com
}

Received: June 16, 2018

Accepted: July 25, $2018 \quad$ Online Published: September 27, 2018

doi:10.5539/ies.v11n10p91

URL: https://doi.org/10.5539/ies.v11n10p91

\begin{abstract}
Since broadening the aesthetic experience for young children is an element of early childhood education, aesthetic education is important at this stage. By reading and analyzing related studies, this article aims to give preschool teachers a better understanding of the importance and purpose of aesthetic education in early childhood so young children can receive the appropriate aesthetic education in Taiwan.
\end{abstract}

Keywords: aesthetic education for young children, early childhood education, young children

\section{Introduction}

"Taiwan, good beauty; aesthetic ability from youth, and aesthetic ability from lifelong learning." The above mentioned introduction is the concept of the Ministry of Education's "Aesthetic Education Mid-range Project: The 103 years to 107 years" in Taiwan (The Ministry of Education, 2013). In fact, aesthetic ability in human life is just as important as breathing the air. It is indispensable. Although aesthetic ability is abstract, it is related to the cultivation of the individual's soul and the foundation of national competitiveness (Chen, 2015; Huang, 2015).

The spread of culture depends on aesthetic education to enhance and create the richness and quality of the humanities. In particular, at critical moments of interdisciplinary integration and cultural and creative industries leading the global economic development, through the various types and stages of aesthetic education to cultivate talented individuals with a talent for tasting knowledge, a happy, beautiful art society has been created. It plays a decisive role in the development of nations, and is a boost to national competitiveness (The Ministry of Education, 2013).

Further, many parents in the current society have realized the importance of children's education and realized the early childhood stage is the key to human growth and the starting point for one's life journey. Of course, parents also understand not only useful human resources should be educated, but also children with cultural and artistic temperaments (Fan, 2014). The American education philosopher Greene (1973) pointed out art can help the individual to broaden their existing horizons. Artistic works can enhance the individual's sensitivity and reflexivity, and the process of artistic creation is the process of expressing one's own life. Art is an element of the environment of "beauty." Children need a living education environment with "beauty". Therefore, art education should be implemented from early childhood, so young children can form an appreciation of the "beauty" of the surrounding environment (Fan, 2014), to cultivate the aesthetic ability of children.

"Aesthetic ability from youth, and aesthetic ability from lifelong learning." The abovementioned introduction is the concept of the Ministry of Education's "Aesthetic Education Mid-range Project: The 103 years to 107 years." in Taiwan (The Ministry of Education, 2013). In short, early childhood education is the key to the initiation of aesthetic ability. Promoting aesthetic ability and art education of kindergartens to take begin in the project, inspiring the beauty perception and experience of each young child, and laying the foundation for the life force of aesthetic ability (The Ministry of Education, 2013), is one of the highlights of the education policy in Taiwan. Therefore, by reading and analyzing related studies, this article aims to allow preschool teachers to more fully incorporate aesthetic education in early childhood teaching in kindergartens, and aesthetically cultivates the individual, promoting the competitiveness of our country; with the premise being aesthetic ability is the child's ability to compete in the 21 st century. 


\section{Aesthetic Education of "The Early Childhood Education \& Care Curriculum"}

"The Early Childhood Education \& Care Curriculum", which is promulgated by the Ministry of Education in Taiwan, pointed out kindergarten education should pay attention to the unique development tasks of young children at this stage and pay close attention to the young children's physical movements and health, cognition, language, society, emotion and beauty. As to the overall goal, it points out early childhood education is the basis of all education stages. The implementation of kindergarten education must be closely coordinated with the family and the community to achieve the following goals: First, to maintain the physical and mental health of young children; second, to develop good habits in young children; third, to enrich young children's life experience; fourth, to enhance the concept of young children care; fifth, to develop habits of young children in groups; sixth, to expand the aesthetic experience of young children. The above discussion mentioned kindergarten education should pay close attention to the development of young children's aesthetic ability, and expanding the experience of young children's aesthetic ability is one of the goals of early childhood education in Taiwan. The development of aesthetic experience for young children can be accomplished through aesthetic education (The Ministry of Education, 2017).

\section{Exploring the Importance of Aesthetic Education for Young Children in Taiwan}

Aesthetic education is of great importance in promoting cultural diversity and the development of young children's physical, mental, emotion and personality. Therefore, each child is required to perform aesthetic education (Denac, 2014), so it is important to understand the importance of aesthetic education for young children in Taiwan. The author further analyzes the importance as follows:

\subsection{Aesthetic Education Emphasizing the Beauty of the Soul and Culture Is Important in the Current Society}

The value of human life is often determined by the environment in which people live. The human environment, due to the constant evolution of human culture, forms a variety of different styles, expresses the beauty of different levels, and gradually increases the value of life. Analyzing this viewpoint of aesthetic education reveals the following levels. In a primitive society, human beings are mostly in the ecological environment, which shows natural beauty. In the agricultural society, human beings are mostly in the community environment, which reveals worldly beauty. Progressing to the industrial and commercial society, most human beings are in a civilized environment, and the performance is artificial. Finally, most people reach a moral environment, where they show the beauty of conscience (Gong, 1990).

However, as far as educational fields are concerned, due to confusions in values and changes in social patterns in post-modern culture, students are deeply puzzled about the meaning and value of their life, while educational situations provide a very limited opportunity to discuss spiritual aspects, resulting in the main source of students' personal and social problems. However, aesthetic education emphasizing the beauty of the soul and culture plays an important role in current society (Liu, 2008).

In addition, the leaders of the new century must be able to live in a globalized, information-based, technologically advanced, diverse, and industrially competitive and diverse world. Eight key capabilities are proposed in the EU Conference in 2001. Eight key capabilities are as follows: the ability to communicate in the mother tongue; the ability to communicate in foreign languages; the ability to learn in a position, ability to learn how to learn (including time management, problem solving, information gathering and effective use, and the ability to manage personal careers), interpersonal and social interaction ability, entrepreneurship, and the ability of cultural expression. Among them, the ability of cultural expression is also called "aesthetic ability" or "aesthetic education." This means the aesthetic ability to appreciate creativity, experience sound and music, literature, and art, which is the very basis of education (Jian, 2008). In this regard, "aesthetic education" is also the foundation of early childhood education and the ability to appreciate and creatively teach children in pottery. The implementation of aesthetic education should begin in the early childhood stage (The Ministry of Education, 2013), highlighting the importance of "aesthetic education" for young children in Taiwan.

\subsection{Aesthetic Education for Young Children Is the Basis of Early Childhood Art Education}

Aesthetic ability is the cultural expression of the eight key competences put forward by the European Union in 1999. This means one can appreciate creativity and experience various aesthetic experiences, such as music, literature and art. The aesthetic ability is "appreciation of the beauty, the sensibility of the beauty, and then the ability to create beauty" (Jian, 2008), and people are gradually aware of the contribution of aesthetic education in teaching, so the arts in early childhood education will be seen as a very important aspect in many countries (Apps \& MacDonald, 2012; Twigg \& Garvis, 2010).

However, why do young children need to learn art? What is the value of art for young children? What is the 
importance of art for young children? Bell (2012) pointed out the learning in various kinds of art is a kind of high-value learning. It can enrich children's wider education experiences. Fröbel believed young children are born with four kinds of instinct: activity instinct, cognitive instinct, artistic instinct and religious instinct. Although children's abilities in many aspects have not yet matured, they gradually cultivate their aesthetic abilities in the course of their first few years of life. For example, the children's daily graffiti and stacking wood games, or the likes and dislikes of colors, textures, and appearances of clothes, food, and toys. It can be seen young children at this stage have begun to engage in artistic creation or aesthetic judgment activities. Art and young children are a natural combination, and art education has always been an essential element of the early childhood education curriculum (Lü, 2009).

In further analysis, art education guides children's observation, imagination, thinking, design and innovation, so they have the ability to cope with the environment, through the appreciation and performance of the arts, make children happy and achieve a happy life. Creators express their inner thoughts and feelings through visual images, rhythm, body movements, and dramatic plays. Their works have aesthetic value and can attract viewers' recognition and resonance, which can be called art. The art curriculum in early childhood education includes arts and crafts, music, drama, and rhythm (Wu, 2011).

The aesthetic education for young children is the basis of early childhood art education, and it is the basic method to enhance children's appreciation of beauty. These experiences will be the seed of the child's future artistic activities, opening the child's interest in engaging in artistic activities, and stimulating children's lively and rich imagination and creativity. Children have many learning abilities and can create and develop learning motives through art gamification. Parents who artistically educate and nurture the young age of their children greatly influence their future personality formation, psychology, emotions and values; at the same time, they indirectly influence the child's learning attitude and mind in the future (Fan, 2014 ), so the importance of aesthetic education for young children is clear.

\subsection{Aesthetic Education of Young Children Is the Hall for Accomplishing the Mission of Early Childhood Education}

Aesthetic education is based on "aesthetics" or "art philosophy." Aesthetic education is also a thing that can produce good feelings. It can be cultivated through the learning method, and can contribute to the enrichment and improvement of life culture, as compared with art education (Gong, 1990). Art education and aesthetic education are closely related to each other. People generally associate art education with aesthetic education. This is why aesthetic education will pay special attention to art education. Therefore, art education is an essential element of the aesthetic education curriculum. Further, Smith believed the purpose of art education is to learn in art and develop aesthetic abilities. Greene argued art education can enhance children's expression of perceptions, feelings, and thoughts through using pigments, clays, sounds, words, or body movements. Burton also pointed out students are expected to transform their personal experiences into aesthetic expressions through drums and cymbals. Through creative thinking, they present things and appearances of life and enhance their artistic meaning and appreciation. To enhance aesthetic appreciation and perception, art education must develop personality traits such as creative imagination and expression, as well as confidence, perseverance, and critical perception. Therefore, these educational methods of aesthetic experience and activities, and the philosophy of early education philosophers, argue "promoting the progress of individuals and society and strengthening the development of human nature" are very important. As Robinson emphasized, we are not simply living in the life of the industrial economy. We need different educational approaches to achieve better goals, and this alternative approach to education is in the domain of aesthetic education (Chen, 2009).

\section{Exploring the Purpose of Aesthetic Education for Young Children in Taiwan}

The ultimate goal of education is to cultivate a person's nature. The methods it uses are both "scientific" and "artistic" (Chen \& Lu, 2009). However, the aesthetic orientation in the education process is neglected. In fact, the spiritual activities of human beings are pluralistic. The enlightenment and development of unified education are the fundamental requirements of education, and also the most important for human beings to accomplish. Aesthetic education can capture the full range of people's spirit and cultivate balanced development of the moral and intellectual facets of life. As Schiller says: "The successful realization of the concept of human nature is beautiful," advocating the cultivation of unified personality through aesthetic cultivation (Chen, 1998).

The sense of beauty is not about training children with skills and instilling children's memory knowledge as a priority; it involves cultivating children's sensibility, expressiveness, and imagination. In aesthetic education, aesthetic education is basically cultivating people's aesthetic qualities, and people have the ability to sense beauty, the knowledge, feelings, and habits of beauty (Chen, 2008). In this regard, aesthetic education cultivates the beauty 
qualities of young children and enables them to have the knowledge, feelings, and habits of beauty, thus fulfilling the mission of early childhood education. Therefore, we must first arouse children's awareness and perception of beauty, and then allow them to become appreciators or life practitioners. Aesthetic education does not necessarily turn children into experts, but it will make them become the people they want to become. By displaying how their life tastes everywhere and anytime; if this person still has aesthetic potential and opportunity, he or she can also bring their creativity out (Chen, 2015). Second, aesthetic education is at the core of education and its scope is extremely wide. Through aesthetic education, it is possible to strengthen learning in different disciplines (Chen, 2008). In this way, aesthetic education for young children is the core of early childhood education. With aesthetic education, young children can learn in different areas (body movements and health, cognition, language, society, and emotions). The purpose of aesthetic education for young children is to cultivate the children's unified personality through aesthetic education and build children's sensibility, expressiveness, and imagination. We must also awaken the children's awareness and perception of beauty, and then allow them to be able to appreciate and fully engage in life in the future. They also have the potential and opportunity for aesthetics, and they can develop their own creativity. The Ministry of Education (2017) stipulated the goals of the aesthetic field are: (1) to like to explore the beauty of things; (2) to enjoy aesthetic experience and artistic creation; (3) to display rich imagination; (4) respond to the feelings and preferences of artistic creation. In summary, the author analyzes related documents (Lin, 2012; Shih, 2002; The Ministry of Education, 2012; Chen, 1998; Chen, 2015; Chen, 2008). The purpose of aesthetic education for young children is as follows:

1) Let young children like to explore the beauty of things and cultivate young children's sensibility towards the living world.

2) Liberate young children's art instincts.

3) Stimulate young children's imagination and creativity

4) Enhance the expression of young children's affection and beauty

5) Let children naturally recognize the beauty of life and accumulate children's aesthetic qualities

6) Shape the values of young children's beauty and goodness, and derive the ability to care for others, the environment, and society

7) Transform young children's negative emotions, and the above assist in bringing young children's personality into unity and harmony.

\section{Conclusion}

The Greek philosopher Plato once said: "Before children are taught to distinguish between truth and good, children must be taught to experience beauty." Plato also regarded aesthetic education as the foundation of all education. Schiller, the German philosopher of aesthetic education, said "Only through aesthetic education can people's sensibility, rationality and spirituality be harnessed to achieve harmonious development, so as to create a perfect personality and promote the establishment of a harmonious society" (Chen \& Lu, 2009). In fact, aesthetic education is at the core of education. Aesthetic education is an educational activity that makes it easier for the educated to obtain aesthetic experience and allowing one to bathe in the feelings of beauty. In other words, it enables the educated to form a so-called appreciation and a feeling of beauty, and then create a beauty of themselves (Chen, 1998). Aesthetic education is a means of education allowing children to possess the qualities of beauty. This aesthetic literacy is not confined to traditional concepts. It is thinking and talking about the uniqueness of things. Literacy is itself an instinct and a process of communication between individuals and the outside world (Chen, 2008). This article aims to allow preschool teachers to more fully incorporate aesthetic education in early childhood teaching, exploring the importance and purpose of aesthetic education for young children to make preschool teachers understand its essence, to aesthetically cultivate the individual, and promote the competitiveness of our country.

By reading and analyzing related studies, the importance of aesthetic education for young children can be summarized as follows: (1) aesthetic education emphasizing the beauty of the soul and culture is important in the current society, (2) aesthetic education for young children is the basis of early childhood art education, (3) aesthetic education for young children is the hall for accomplishing the mission of early childhood education. The purpose of aesthetic education for young children can be summarized as follows: (1) let young children like exploring the beauty of things and cultivating young children's sensibility towards the living world, (2) liberate young children's art instincts and awaken children's untapped appreciation of the beauty of life, (3) stimulate young children's imagination and creativity, enhancing the expression of young children's affection and beauty, (4) let children naturally recognize the beauty of life and accumulate children's aesthetic qualities, (5) shape the values of young 
children's beauty and goodness, and derive the ability to care for others, the environment, and society, (6) transform young children's negative emotions, so young children's personality will be more unified and harmonious.

\section{References}

Apps, L., \& MacDonald, M. (2012). Classroom aesthetics in early childhood education. Journal of Education and Learning, 1(1), 49-59. https://doi.org/10.5539/jel.v1n1p49

Bell, D. (2012). Talking about art with young people: Conversational strategies for aesthetic learning in early childhood settings. International Art in Early Childhood Research Journal, 3(1), 1-17.

Chen, B. H. (2015). The aesthetic ability comes from awareness and perception of beauty. In the Ministry of Education (Ed.), Building the aesthetic ability: Bring new touches for life (pp. 6-7). Taipei City: The Ministry of Education.

Chen, C. H. (2008). The concept and practice of aesthetic education. Teacher World, 153, 4-9.

Chen, M. J. (1999). Research on the idea and interpretation of aesthetic education. Presented at the Seminar on Interpretation and Dialogue of Whole Person Education and Aesthetic Education. Center for Teacher Education of National Taiwan Arts Institute, Taipei County.

Chen, Y. R. (2011). The development and trend of American art education. Nantai Journal, 36(4), 97-112.

Denac, O. (2014). The significance and role of aesthetic education in schooling. Creative Education, 5, 1714-1719. https://doi.org/10.4236/ce.2014.519190

Fan, R. Z. (2014). How to cultivate children's art and the aesthetic ability. Retrieved from http://www.benesse.com.tw/educate/essay.asp?vid=2605

Gong, B. S. (1990). Aesthetic education is the hall for fulfilling educational mission. In the Department of Education, National Taiwan Normal University (Ed.), Principles of Education (pp.1-15). Kaohsiung City: Fuwen.

Huang, G. N. (2015). Feeling the beauty which starts from the "stay distance, hold respect." In the Ministry of Education (Ed.), Building the aesthetic ability: Bring new touches for life (p. 8). Taipei City: The Ministry of Education.

Jian, J. C. (2008). The creative activities of parent-child music electronic picture book influence children's artistic ability. The dissertation was published in the "Publishing Meeting of 97 School Teachers and Academic Achievements of the School of Humanities and Management" organized by the University of Science and Technology of Fooyin, Kaohsiung County.

Liu, F. R. (2008). The new thinking of the current aesthetic education: A preliminary exploration of the spirit-oriented whole-person aesthetic education concept. Teacher World, 153, 10-15.

Shih, Y. H. (2002). The transformation and practice of Confucius' teaching art. Journal of Elementary Education, 14, 269-284.

The Ministry of Education. (2013). Aesthetic education mid-range project: The 103 years to 107 years. Taipei City: The Ministry of Education.

The Ministry of Education. (2017). The early childhood education \& care curriculum. Taipei City: The Ministry of Education.

Twigg, D., \& Garvis, S. (2010). Exploring art in early childhood education. The International Journal of the Arts in Society, 5(2), 194-204.

Wu, X. Z. (2011). An Action Research on Integrating Mangrove Environmental Education into Teaching Arts to Young Children-A Case Study at the Affiliated Kindergarten of Po-He Elementary School (Unpublished master dissertation). Hsinchu: National Hsinchu University of Education.

\section{Copyrights}

Copyright for this article is retained by the author(s), with first publication rights granted to the journal.

This is an open-access article distributed under the terms and conditions of the Creative Commons Attribution license (http://creativecommons.org/licenses/by/4.0/). 